\title{
Teachers and STEM Education: Collaboration across Disciplines and Implementation of Lessons in Two Subject Areas
}

\author{
Tang Minh Dung*, Vu Nhu Thu Huong, Nguyen Thi Nga \\ Department of Mathematics and Informatics, Ho Chi Minh City University of Education, Vietnam
}

Received June 1, 2020; Revised July 16, 2020; Accepted August 10, 2020

\begin{abstract}
Cite This Paper in the following Citation Styles
(a): [1] Tang Minh Dung, Vu Nhu Thu Huong, Nguyen Thi Nga, "Teachers and STEM Education: Collaboration across Disciplines and Implementation of Lessons in Two Subject Areas," Universal Journal of Educational Research, Vol. 8, No. 9, pp. 4122-4128, 2020. DOI: 10.13189/ujer.2020.080938.
\end{abstract}

(b): Tang Minh Dung, Vu Nhu Thu Huong, Nguyen Thi Nga (2020). Teachers and STEM Education: Collaboration across Disciplines and Implementation of Lessons in Two Subject Areas. Universal Journal of Educational Research, 8(9), 4122-4128. DOI: 10.13189/ujer.2020.080938.

Copyright $\subseteq 2020$ by authors, all rights reserved. Authors agree that this article remains permanently open access under the terms of the Creative Commons Attribution License 4.0 International License

\begin{abstract}
One of the difficulties of implementing STEM education in Vietnamese secondary school is the conflict between STEM education's interdisciplinary characteristics and the current monodisciplinary teaching in Vietnam. In this context, the paper mentions some scenarios from the collaboration of the teachers from different disciplines to develop and implement STEM education in high school, but these scenarios still retain the specific characteristics of each subject. Deriving from the ideas of the STEM product that is a spring scale, the teachers analyzed the program and textbooks to identify relevant knowledge. Then, applying the Engineering Design Process, two STEM lesson plans were designed and taught experimentally by a Mathematics teacher and a Physics teacher. For Mathematics, students collected data about the length of spring after hanging heavy objects. Then, working in the transformations between many functional registers like table, graph and algebraic expression, they found that the relationship between the length of the spring and the weight of the heavy object can be expressed by a linear function. For Physics, the experiment of measuring the displacement of the spring allows students to discover the invariants of the ratio between elastic force and the displacement of the spring (according to Hooke's law). In the end, the student successfully created portable spring scales in different ways. Therefore, these situations are proof to promote the natural science-subjects teachers' collaboration through the dominant perception as well as the contribution of each
\end{abstract}

discipline in designing and implementing a STEM activity in the future.

Keywords STEM Education, Interdisciplinary, Collaboration, Linear Function, Hooke's Law

\section{Introduction}

In international integration, STEM education has emerged as a new teaching trend in recent years, and it has attracted the attention of educational institutions in Vietnam. Indeed, we can find the term "STEM education" in many documents of educational management. In particular, STEM education has been officially mentioned in Vietnam's new general education curriculum, which commences implementation in September 2020.

STEM education can be approached from a variety of perspectives, but educators all agree on its interdisciplinary nature because STEM education directs learners to solve real-life problems by practice $[3,9,14]$. Real-life problems are often complicated and thus require learners to choose the most appropriate of the possible approaches, or sometimes a combination of different approaches. Therefore, learners do not have to mobilize specific knowledge, skills, and thinking provided by subjects in the school, but they need to understand how they interact and support themselves. However, the current situation of Vietnamese education has not yet fully prepared for the 
interdisciplinary of teacher training and the organization of school professional activities. This fact poses many difficulties for the implementation of STEM education in schools.

According to El Nagdi et al.[2], there are two directions to implement STEM education in a school. Firstly, a specialized teacher is responsible for a STEM teaching course. Nevertheless, this approach is challenging in practice due to the epistemological constraints of disciplines, especially in the lack of such teachers trained in pedagogical universities. In the second direction, the teachers of disciplines (Physics, Chemistry, Biology, Technology, Mathematics) gather together to develop and implement STEM activities. This model is encouraged by many researchers because it is appropriate for the discipline-oriented teacher training context $[1,11,13]$. In this direction, the issue that we are interested in is developing a collaborative way among teachers of different disciplines to develop and implement STEM lesson plans in the Vietnamese context.

\section{Method}

In this article, we provide a case study of the collaboration across disciplines and the implementation of lessons in two subject areas, namely Mathematics and Physics. Our study is based on the lesson study theory that is widely used in research on teachers' collaborative work. This theory is an operational framework that can be referenced, but it needs to be supplemented to be implemented in the case of many teachers in different disciplines working together in collaboration. Our study has only been conducted on the first four steps in eight steps of the lesson study $[10,12]$ following.

1. Defining the problem

2. Planning the lesson

3. Teaching the lesson

4. Evaluating the lesson and reflecting on its effects

In the first step, the idea originated from a collaboration between Science teachers (Physics, Chemistry, Biology) and Mathematics teachers supported by a group of mentors from Sciences and Mathematics departments of Ho Chi Minh City University of Education to develop and implement STEM education in high school. Initially, a Physics teacher, after many exchanges among members of STEM team teachers, proposed to teach Hooke's Law with STEM product as a portable spring scale. From a mathematical perspective, Mathematics mentor saw that Hooke's Law could be used to approach the linear function, and then she exchanged this idea with secondary school teachers. Therefore, this idea is not only a result of a discussion in a harmonious collaboration among teachers of different disciplines but also allows us to shape a STEM setting where Physics or Mathematics teachers can develop in different ways. Thus, teachers can emphasize and see the role of a particular discipline.
In the second step, we analyze two institutions of Physics and Mathematics teaching in grade 10 through programs and textbooks to find the connections and opportunities that allow a form of integration of interdisciplinary Mathematics and Physics and solve the same practical problem of making a portable spring scale. The STEM lesson plans are designed according to the engineering design process (EDP) - an organized, open-ended approach to investigation that promotes creativity, invention, prototype design, testing and analysis. According to Jolly [4], the EDP steps (Figure 1) are not necessarily in sequence and may each be repeated as many times as needed. Students can make improvements in their solutions along the way. These iterative steps will involve students in asking critical questions about the problem and guide them through creating and testing actual prototypes to solve that problem.



Figure 1. Engineering Design Process (EDP)

In the third step, a mathematics teacher and a physics teacher take two teaching sessions according to lesson plans in the second step. In particular, a teacher (Mathematics/Physics) will directly guide students in STEM activities and other teachers observe and play the role of a support specialist when needed.

In the fourth step, teachers will discuss students' STEM products and evaluate the performance developed from STEM lesson plans.

Below, we will introduce more detail about shaping STEM activity, analyzing the teaching context, and developing the teaching scenario of two STEM lesson plans. They are directed toward a portable spring scale, but each emphasizes a particular discipline - the first highlights Mathematics with the linear function and the second, Physics with Hooke's Law.

\section{Results}

\subsection{Program and Textbook Analysis}

In Physics 10, the lesson "Elastic force of the spring. 
Hooke's Law" focuses on studying the direction, setpoint and magnitude of the spring-force vector when there is an act of deforming the spring (stretching or compressing) [7]. The formula for Hooke's law $\mathrm{F}=\mathrm{k} .|\Delta \mathrm{l}|$ denotes the proportional relationship between the magnitude of the elastic force and the displacement of the spring. Mathematically, this formula is associated with the algebraic form of a functional relationship between two quantities: the independent variable is the displacement of the spring, and the dependent variable is the magnitude of the elastic force. This formula has been studied in Algebra 10 a few weeks earlier.

In Algebra 10, the linear function (presented in the lesson "Function $\mathrm{y}=\mathrm{ax}+\mathrm{b}$ ") has major content focusing on the review of deterministic sets, various tables and graphs [8]. This knowledge in textbooks is presented purely in mathematics, completely lacking situations associated with reality as well as practice activities and experiences for students. Although, when learning this knowledge in Mathematics, 10th-grade students have not yet studied Hooke's Law in Physics, they have learned two lessons that are strictly related to the above section, which is lesson 9 "Elastic force" (Physics 6) and lesson 10 "Dynamometer Force measurement. Weight and mass" (Physics 6) [6]. Thus, students know that the spring is elastic, the elastic force is generated when having a deformation of the spring, and the higher the deformation, the higher the elastic force. However, how much is the magnitude of this force, and how to calculate it are not mentioned. The dynamometer allows determining the magnitude of this force. That means 10th-grade students already knew how to use this device, and its components are indicator needles, scale tables and springs.

\subsection{Ideas on the Topic of STEM}

The above analysis shows that the portable spring scale is a STEM product that connects two fields of learning, Mathematics and Physics (linear function and Hooke's Law).

The topic "Portable spring scale" can be implemented in a STEM activity with four components:

Science (S): Hooke's law, equilibrium conditions of point, gravity.

Technology (T): suitable material for making spring scales (springs have good elasticity and suitable hardness) and the scale (as something produced by students).

Engineering (E): building and testing the scale (engineering process).

Mathematics (M): proportions of two quantities (the mass/weight of the heavy object and the displacement of the spring); the dependent relationship of function $y=a x$.

These questions need to be addressed: Which teacher will teach STEM lessons with the spring scale? Is it possible to implement them in both subjects? How to build situations in these two areas?

The following two situations are designed to teach the lesson "Elastic force of springs - Hooke's Law", in Physics 10 and "Function $\mathrm{y}=\mathrm{ax}+\mathrm{b}$ " in Algebra 10 in STEM education-oriented, specifically:

- In Physics 10, experimental situations concern the relationship between the magnitudes of the elastic force (F) and the displacements $|\Delta \mathrm{l}|$ of the spring via the expression $\mathrm{F}=\mathrm{k} .|\Delta \mathrm{l}|$, where $\mathrm{k}$ is the hardness of the spring.

- In Algebra 10, experimental situations concern the relationship between the lengths (y) of the spring and the weights ( $x$ ) of heavy objects $y=a x+b$, where $b$ is the original length of the spring, and $a$ is the rate of deformation of the spring by weight (also the hardness of the spring).

\subsection{Two STEM Lesson Plans in Mathematics and Physics}

The EDP guided our lesson plans with 5 phases that we summarize in Table 1. By constructing the table using the engineering design process, the teachers were able to identify five phases and how Mathematics and Physics concepts are integrated at each phase.

Table 1. Summarize phases structure of two STEM lesson plans

\begin{tabular}{|c|l|l|l|}
\hline Phase & Engineering design process & \multicolumn{1}{|c|}{ Objectives } \\
\hline 1 & Define the problem & Make a portable spring scale so that it can weigh a maximum weight of 500gr. \\
\hline 2 & Research & $\begin{array}{l}\text { Mathematics } \\
\text { Given weight (P), determine the length (1) of } \\
\text { the spring. }\end{array}$ & $\begin{array}{l}\text { Physics } \\
\text { Given weight (P), determine the displacement } \\
(\Delta \mathrm{l}) \text { of the spring. }\end{array}$ \\
\cline { 3 - 4 } & $\begin{array}{l}\text { Determine the formula between the length y } \\
\text { (i.e., l) of the spring scale and weight } \mathrm{x}(\mathrm{i} . \mathrm{e} ., \mathrm{P}) \\
\text { for getting function: } \mathrm{y}=\mathrm{ax}+\mathrm{b}\end{array}$ & $\begin{array}{l}\text { Determine the formula between the force } \mathrm{F}(\mathrm{i} . \mathrm{e} ., \\
\text { weight }(\mathrm{P}) \text { ) and the displacement }(\Delta \mathrm{l}) \text { of the } \\
\text { spring for getting Hooke's law formula: } \mathrm{F}=\mathrm{k} .|\Delta \mathrm{l}|\end{array}$ \\
\hline 3 & Imagine - Plan & $\begin{array}{l}\text { Discuss the design (shape, size, how to create the scale, ...) } \\
\text { Draw a design }\end{array}$ \\
\hline 4 & $\begin{array}{l}\text { Create - Test and evaluate }- \\
\text { Redesign }\end{array}$ & $\begin{array}{l}\text { Build, create a spring scale from given items. } \\
\text { Test with some items. } \\
\text { Redesign if necessary. }\end{array}$ \\
\hline 5 & Communicate & Use the spring scale to measure the weight of the given item. (Game challenge) \\
\hline
\end{tabular}




\subsection{Scenarios}

In the following scenario (Table 2), the first three phases of the series of activities designed for the same topic "Portable spring scale" in Mathematics and Physics are focused.

Table 2. Five phases of the series of activities designed for the same topic "Portable spring scale" in Mathematics and Physics

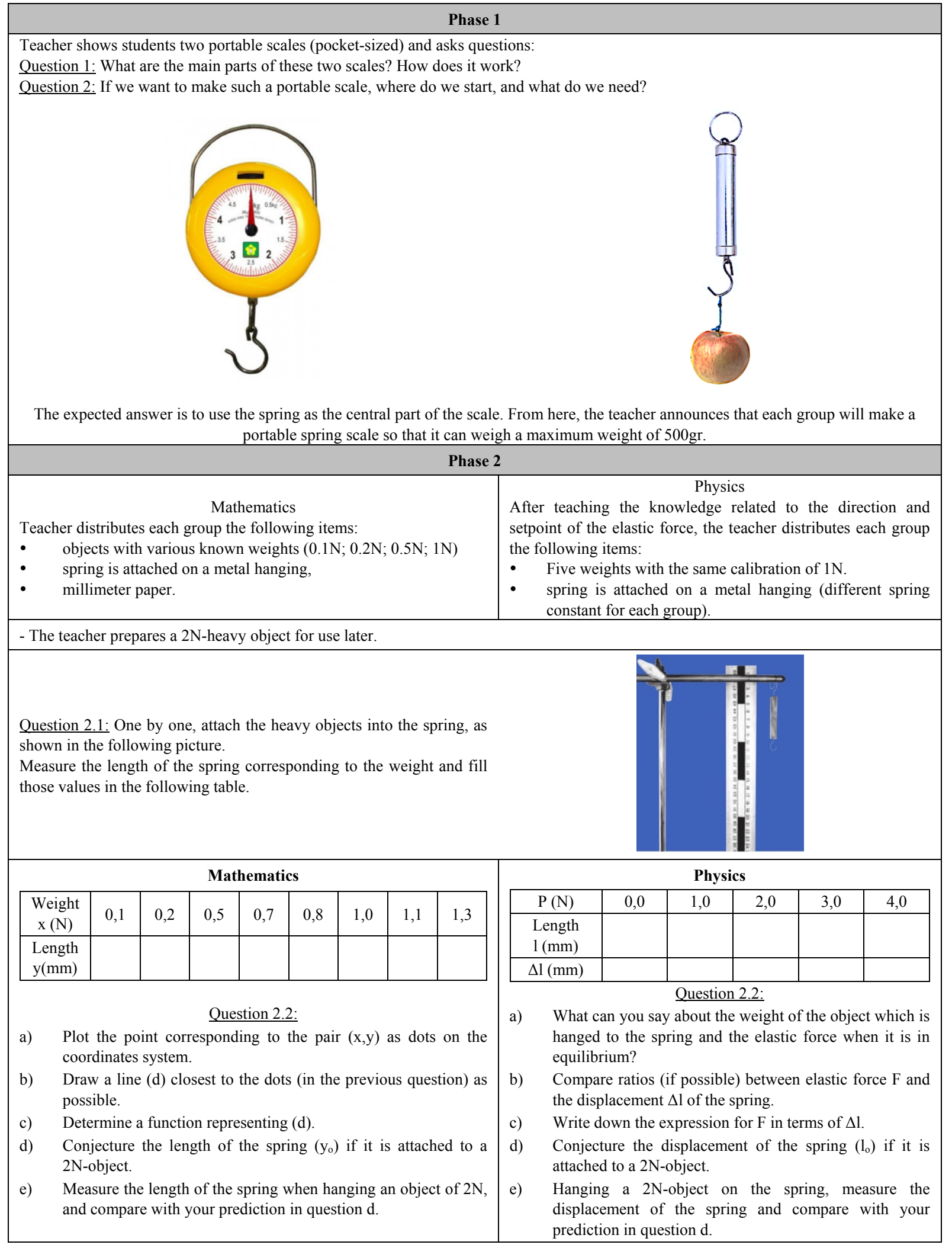




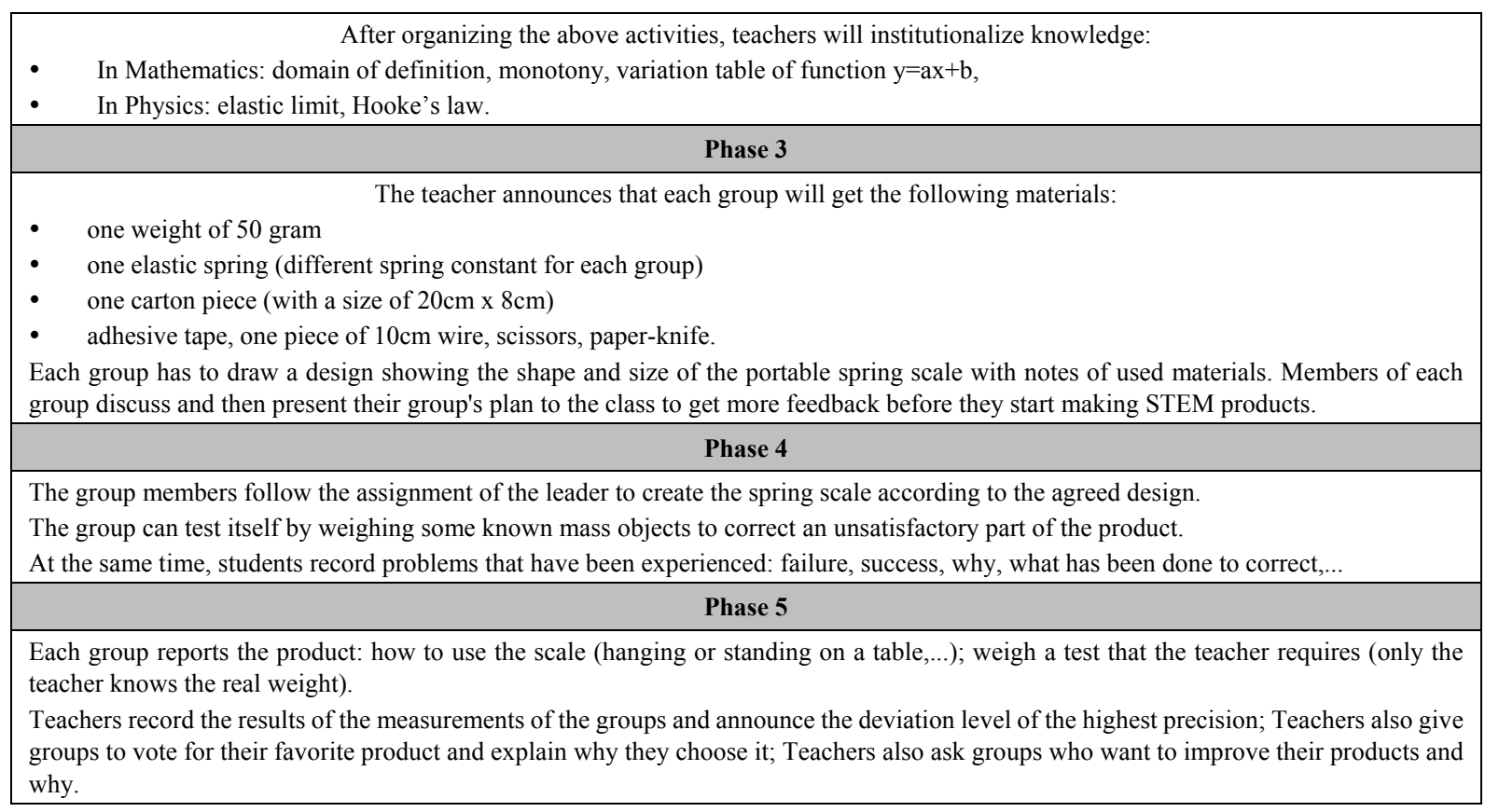

\subsection{Experimentation and Evaluation}

The two lesson plans mentioned in Table 2 are designed in line with the need to solve practical problems, are implemented under the EDP process and accurately convey the knowledge in the program (Physics and Mathematics) in the direction of strengthening activities and developing learner's competences.

The two technological and technical elements have the same role and meaning in both mathematics and physics lessons, which are allowing students to practice, manipulate tools, and choose materials, drawing design, and construction products.

\section{a) Mathematical Perspective}

The linear function is not traditionally approached from a given mathematical formula. However, it has been formed from the study of a practical situation associated with an elastic spring where the students have to collect data about the length of spring after hanging heavy objects with predetermined weights.

Students make transformations between functional registers: Table $\rightarrow$ Graph $\rightarrow$ Algebraic expression. (Figure 2)

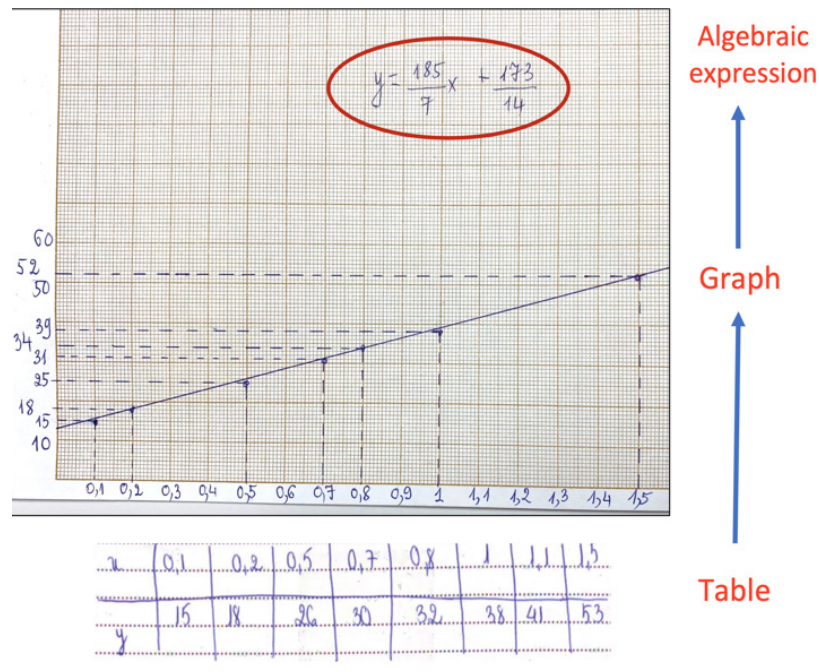

Figure 2. The transformation between functional registers: table, graph, algebraic expression

When the students of this group make a portable spring scale, they use the graph paper to make its scale. They explain how to read the index as follows: when hanging heavy objects on the lower hook of the spring, the needle pointing to the length on the axis (positive direction is downward as shown), we just need to search horizontally (from right to left) to find the point on the line and then "read" the coordinates of this point to get the weight of the measured object (Figure 3). 


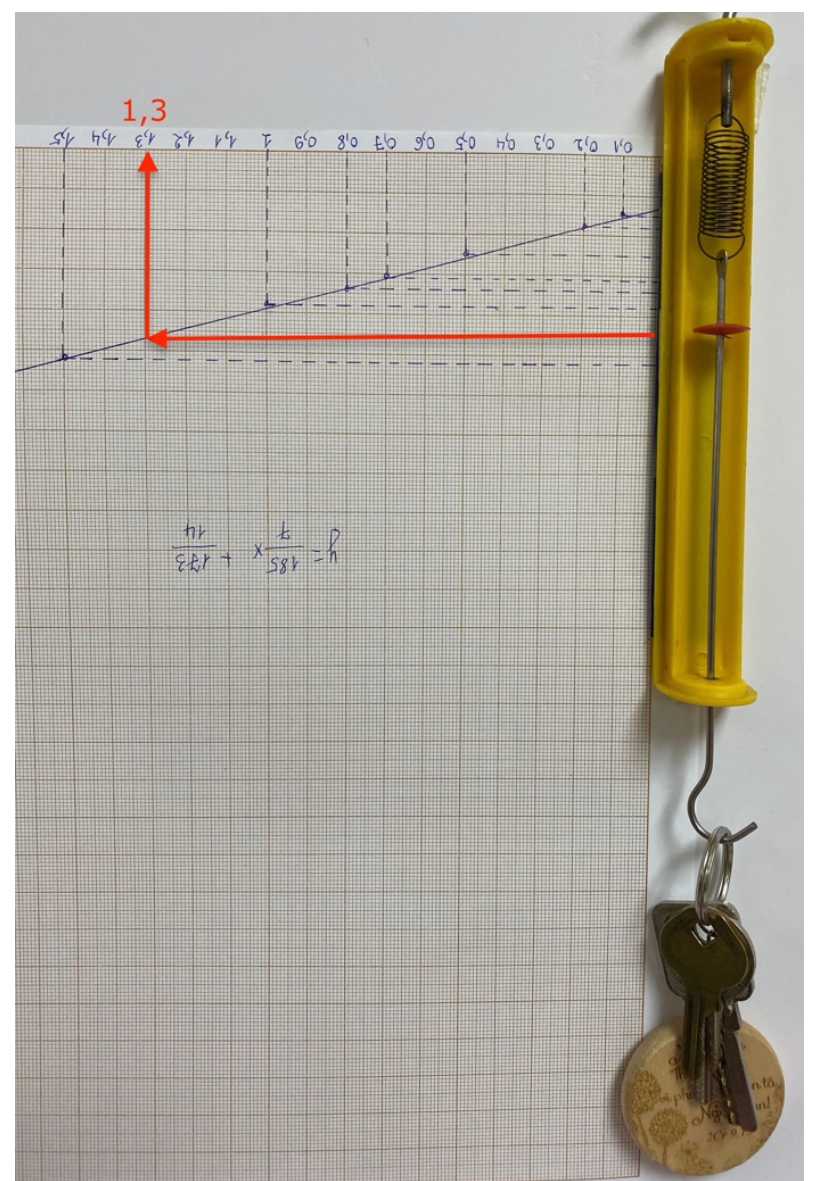

Figure 3. Product of student's work

In general, when participating in STEM education-oriented learning with these lesson plans (both in Physics and in Mathematics), students have the opportunity to participate in the practice of measurement (spring length). Moreover, they participate in the scientific research process (experimentation, prediction, verification and conclusion).

\section{b) Scientific Perspective (Physics)}

The experimental situation for measuring length and displacement of the spring allows students to discover the invariants of the ratio between elastic force $\mathrm{F}$ and the displacement of the spring. Following the characteristic of experimental science, physics teachers do not need to prove it as in Mathematics but "acknowledge" this result is Hooke's law based on physicist Robert Hooke's announcement.

With the requirement to set up a scale with only one weight of 50 grams, students must mobilize the knowledge of Mathematics to calculate the proportional ratio of two quantities: mass and displacement of the spring. Correctly, the displacement $l_{o}$ of the spring after hanging the object of $50 \mathrm{gr}$ is repeated in equal successive segments to have a measuring line corresponding to $100 \mathrm{gr}, 150 \mathrm{gr}, \ldots$ In contrast, when this displacement $l_{\mathrm{o}}$ is divided by 5 , we get 5 tick marks for the masses of $10 \mathrm{gr}$, 20gr, 30gr, 40gr, 50gr
(Figure 4).

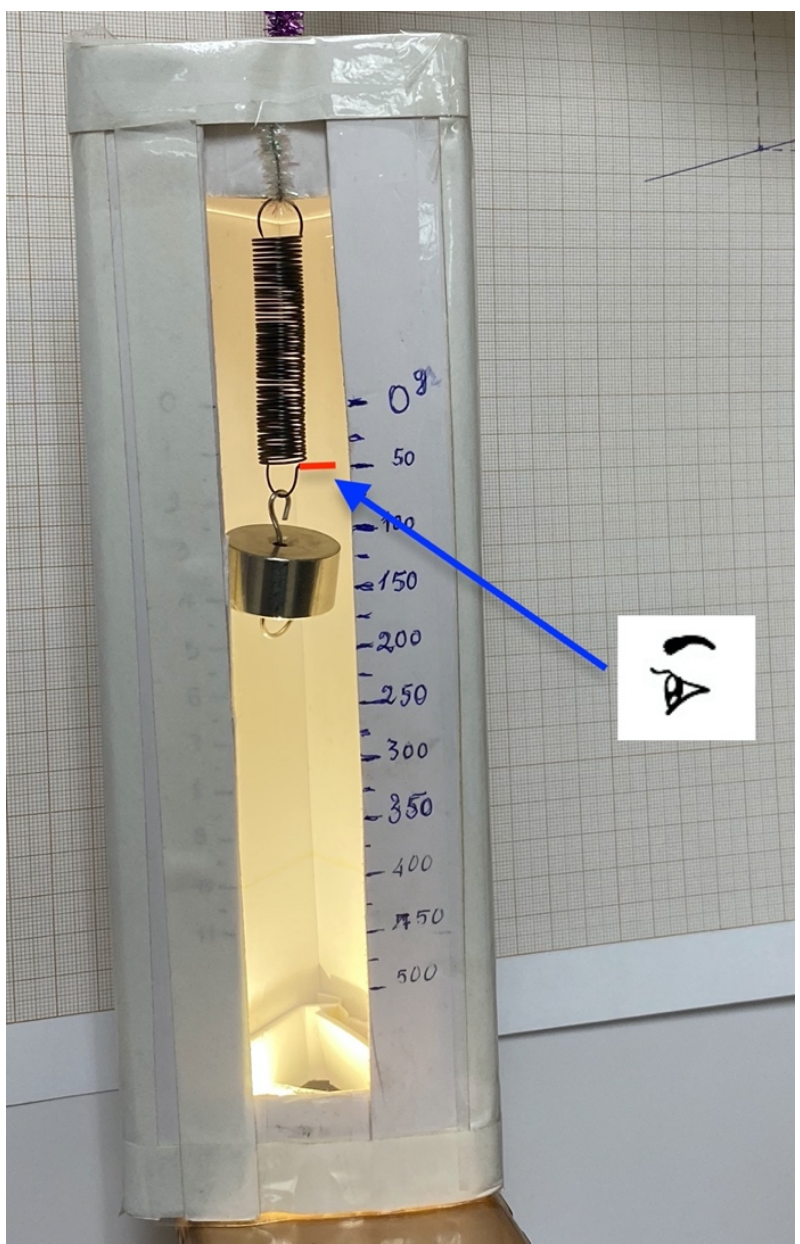

Figure 4. Student's STEM product: portable spring scale

\section{Conclusions}

Our research results show the possibility of cooperation among teachers in different disciplines in building and developing a STEM lesson plan. With the same STEM lesson plan, we can choose the appropriate element for Mathematics or for Physics to emphasize and highlight knowledge of each subject. The built-in situation suggests that exploitation can lead to appropriate STEM lessons for many different subjects from the same idea of STEM products.

The next problem is how to get teachers out of the silo in a "safe" area of professional knowledge, join in the STEM integration teacher groups, and provide them with additional pedagogical knowledge, necessary and suitable skills for STEM education.

In order to effectively implement STEM education in the new Vietnam's educational curriculum, we think that it must increase the following activities:

- High school teachers are organized into STEM groups (including many different subjects) to exchange, discuss, build, and develop STEM topics. 
- The school leader should consider creating a framework (or network) that provides the necessary support (time, money, materials, etc.) to encourage STEM teachers' communities.

Another problem, what do pre-service teachers need to prepare to quickly integrate with the implementation of STEM education in the new program at high schools? We believe that students of the departments of the STEM group of the pedagogical university should be involved in developing a practical problem that involves using STEM concepts. Besides, the pedagogical internships are a good time for pedagogical students to interact and participate in STEM groups at high school [5].

\section{REFERENCES}

[1] H. El-Deghaidy, N. Mansour. Science teachers' perceptions of STEM education: Possibilities and challenges, International Journal of Learning and Teaching, Vol.1, No.1, $51-54,2015$.

[2] M. El Nagdi, F. Leammukda, G. Roehrig, Developing identities of STEM teachers at emerging STEM schools, Online available from https://link.springer.com/article/10.1186/s40594-018-01361

[3] M. Honey, G. Pearson, H.A. Schweingruber. STEM integration in K-12 education: status, prospects, and an agenda for research, The National Academies Press, Washington D.C, 2014.

[4] A. Jolly. STEM by Design, strategies and activities for grades 4-8, Routledge Publishing, New York, 2017.

[5] T.T. Le Thai Bao, M. D. Tang. A collaborative model between teachers - student teachers - lecturers during the Mathematic pedagogical practicum in Ho Chi Minh City University of Education, Ho Chi Minh City University of Education Journal of Science, Vol.17, No.5, 755-765, 2020.

[6] Ministry of Education and Training. Physics 6, Vietnam Education Publishing House, Vietnam, 2014.

[7] Ministry of Education and Training. Physics 10, Vietnam Education Publishing House, Vietnam, 2014.

[8] Ministry of Education and Training. Algebra 10, Vietnam Education Publishing House, Vietnam, 2014.

[9] T.H. Nguyen. STEM/STEAM education: From hands-on to minds-on, Tre Publishing House, Vietnam, 2019.

[10] M. F. Pang, F. Marton. Beyond "lesson study": Comparing two ways of facilitating the grasp of some economic concepts, Instructional Science, Vol. 31, 175-194, 2003.

[11] M. Sanders. STEM, STEM Education, STEMmania, The Technology Teacher, Vol.68, No.4, 20-26, 2009.

[12] J. W. Stigler, J. Hiebert. The teaching gap: Best ideas from the world's teacher for improving education in the classroom, The Free Press, New York, 1999.

[13] M. D. Tang, N. Nguyen Thi, T.T. Le Thai Bao. STEM activity design: the need of cooperation among the teachers of different disciplines, STEM education in the new general education curriculum, 2017.

[14] R. Tytler, G. Williams, L. Hobbs, J. Anderson, Challenges and opportunities for a STEM interdisciplinary agenda, Online available from https://link.springer.com/chapter/10.1007/978-3-030-11066 $-6 \_5$ 